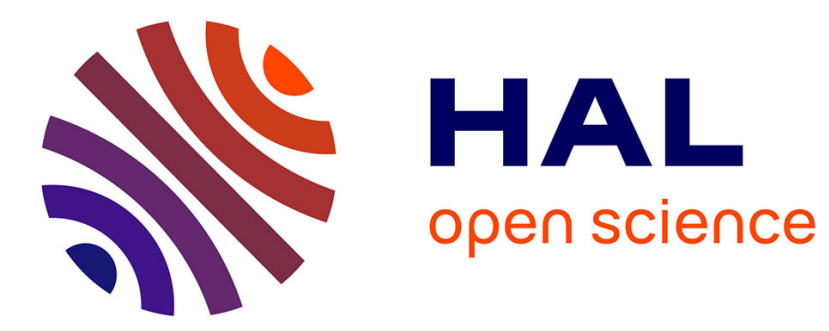

\title{
Drastic lattice softening in mixed triazole ligand iron( ii ) spin crossover nanoparticles
}

Mario Piedrahita-Bello, Karl Ridier, Mirko Mikolasek, Gábor Molnár, William Nicolazzi, Lionel Salmon, Azzedine Bousseksou

\section{- To cite this version:}

Mario Piedrahita-Bello, Karl Ridier, Mirko Mikolasek, Gábor Molnár, William Nicolazzi, et al.. Drastic lattice softening in mixed triazole ligand iron( ii ) spin crossover nanoparticles. Chemical Communications, 2019, 55 (33), pp.4769-4772. 10.1039/C9CC01619H . hal-02335045

\section{HAL Id: hal-02335045 \\ https://hal.science/hal-02335045}

Submitted on 23 Nov 2020

HAL is a multi-disciplinary open access archive for the deposit and dissemination of scientific research documents, whether they are published or not. The documents may come from teaching and research institutions in France or abroad, or from public or private research centers.
L'archive ouverte pluridisciplinaire HAL, est destinée au dépôt et à la diffusion de documents scientifiques de niveau recherche, publiés ou non, émanant des établissements d'enseignement et de recherche français ou étrangers, des laboratoires publics ou privés. 


\section{Drastic lattice softening in mixed triazole ligand iron(II) spin crossover nanoparticles}

Received 00th January 20xx, Accepted 00th January 20xx DOI: $10.1039 / \times 0 \times x 00000 x$
Mario Piedrahita-Bello, ${ }^{1}$ Karl Ridier, ${ }^{1}$ Mirko Mikolasek, ${ }^{2}$ Gábor Molnár, ${ }^{1}$ William Nicolazzi, ${ }^{1}$ Lionel Salmon*1, Azzedine Bousseksou*1
A series of spin-crossover (SCO) coordination nanoparticles (ca. 60 nm) with the general formulae $\left[\mathrm{Fe}(\mathrm{Htrz})_{1+y-x}(\mathrm{trz})_{2}\right.$ $\left.{ }_{y}\left(\mathrm{NH}_{2} \mathrm{trz}\right)_{x}\right]\left(\mathrm{BF}_{4}\right)_{y} \cdot \mathrm{nH}_{2} \mathrm{O}(\mathrm{x}=0,0.1,0.2$ and 0.3$)$ were synthesized in concentrated solutions without using any surfactant or polymer. The nanoparticle powders were investigated by transmission electron microscopy, powder $X$-ray diffraction, magnetometry, calorimetry, Raman/IR spectroscopies, elemental analysis and ${ }^{57} \mathrm{Fe}$ Mössbauer spectrometry. Remarkably, the latter revealed a large decrease of the lattice stiffness when incorporating a small amount of amino-triazole ligand, reflected by the drop of the Debye temperature from $285 K(x=0)$ to $205 K(x=0.3)$. This collapse of the lattice cohesion was attributed to a reorganization of the supramolecular interactions between the Fe-triazole chains. This effect on the SCO properties is also discussed.

Molecular spin crossover (SCO) materials constitute a very active field of research due to their possible application in photonic, electronic and mechanical devices [1-3]. In the past decade, the synthesis of nanometer sized spin crossover materials, the investigation of their size dependent properties and their manipulation at reduced length scales has brought these technological prospects close to reality [4-6]. An important challenge in this context is to preserve the cooperative spin transition properties close to room temperature during the downsizing of the compound at the nanoscale.

The well-known $\left[\mathrm{Fe}(\mathrm{Htrz})_{2}(\mathrm{trz})\right]\left(\mathrm{BF}_{4}\right)$ (trz $=1,2,4$-triazolato) $1 \mathrm{D}$ SCO coordination network [7] is an appropriate candidate for nanoparticle fabrication since it has been shown that its wide thermal hysteresis loop and robust spin transition can be preserved in nanoparticles down to $6 \mathrm{~nm}$ [8]. Despite this advantage, its high spin transition temperature (ca. $380 \mathrm{~K}$ ) is a drawback for a real application. One of the most powerful methods to modulate the spin transition temperature consists

${ }^{1}$ LCC, CNRS \& Université de Toulouse, 205 route de Narbonne, 31077 Toulouse, France

2 ESRF-The European Synchrotron, CS40220, 38043 Grenoble Cedex 9 France

Electronic Supplementary Information (ESI) available: [details of any supplementary information available should be included here]. See DOI: 10.1039/x0xx00000x of partially substituting either the ligand(s), the counteranion(s) or the metal in the material. This 'molecular alloying' approach has been explored both with bulk and nanosized SCO materials, in particular with 1,2,4-triazole based coordination compounds [9-16]. Unfortunately, the experimental analysis and theoretical modelling of the alloy behaviour is arduous and the physical picture remains therefore largely incomplete up to now.

Recently, we have reported the effect of the ligand substitution on the spin crossover properties of mixed triazole ligand iron(II) nanoparticles [16]. Taking into account that the transition temperature of the pure $\left[\mathrm{Fe}\left(\mathrm{NH}_{2} \mathrm{trz}\right)_{3}\right]\left(\mathrm{BF}_{4}\right)_{2}$ complex is around $260 \mathrm{~K}$ [17], a logical decrease of the transition temperature was evidenced when replacing the 1,2,4-4H-triazole by 4-amino- $4 \mathrm{H}$ 1,2,4-triazole. Unfortunately, in the same time, a pronounced decrease of the hysteresis width was also observed. Since the hysteresis (cooperativity) in these compounds has an elastic origin, we have carried out a Mössbauer spectrometric investigation of the elastic properties. Here we report these results, which allow us to put in evidence a dramatic effect of the ligand substitution on the lattice stiffness. This finding not only helps to better understand the SCO behaviour upon ligand substitution, but also provides important insights into the mechanical properties of this emerging class of smart actuator materials [18].

Syntheses of $\left[\mathrm{Fe}(\mathrm{Htrz})_{2}(\operatorname{trz})\right]\left(\mathrm{BF}_{4}\right)$ and the ligand substituted $\left[\mathrm{Fe}(\mathrm{Htrz})_{1+y-x}(\mathrm{trz})_{2-\mathrm{y}}\left(\mathrm{NH}_{2} \mathrm{trz}\right)_{x}\right]\left(\mathrm{BF}_{4}\right)_{\mathrm{y}} \cdot \mathrm{nH}_{2} \mathrm{O}$ nanoparticles were realized in homogeneous media without any surfactant or polymer using highly concentrated solutions. This method, not yet reported for the synthesis of SCO compound, is similar to the precipitation method with an antisolvent to obtain a supersaturated solution $[19,20]$. In fact, traces of surfactants or polymers around the particles can perturb the study of their physical properties and in particular, the SCO and mechanical properties. By decreasing the quantity of the triazole ligand for the benefit of the aminotriazole ligand, a series of compounds with $0(\mathbf{1}), 3.3(2), 6(3)$ and $10 \%(4)$ of the aminotriazole ligand was obtained. TGA revealed increasing quantity of inserted 
water molecules while increasing the amount of the aminotriazole ligands $\left(0.7,0.8,0.85\right.$ and $0.95 \mathrm{H}_{2} \mathrm{O}$ for 1-4, respectively).
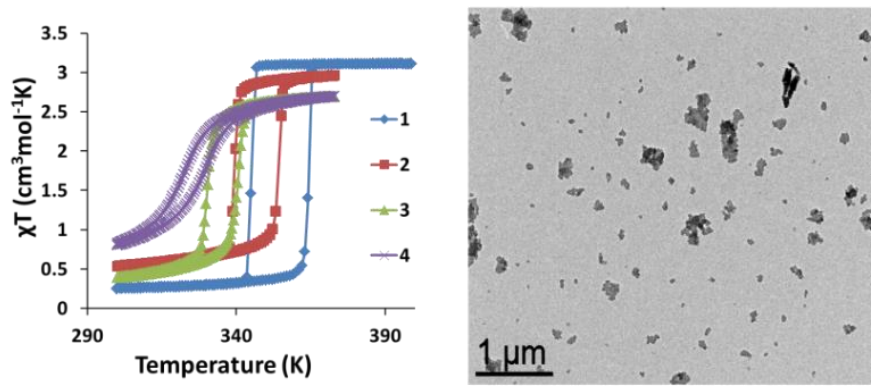

Figure 1. Variable temperature magnetic measurements for samples 1-4. A representative TEM image of nanoparticles of 1 is also shown.

It is interesting to notice that for sample $\mathbf{1}$ inserted water molecules were found in opposition to the corresponding bulk sample. The presence of water molecules was also reported for nanoparticles of 1 synthesized by other methods [16,21] and appears to be dependent on the experimental conditions. From the elemental analysis the suggested compositions are $\left[\mathrm{Fe}(\mathrm{Htrz})_{2}(\mathrm{trz})\right]\left(\mathrm{BF}_{4}\right) \bullet 0.7 \mathrm{H}_{2} \mathrm{O}(\mathbf{1}),\left[\mathrm{Fe}(\mathrm{Htrz})_{2.1}(\mathrm{trz})_{0.8}\left(\mathrm{NH}_{2} \mathrm{trz}\right)_{0.1}\right]\left(\mathrm{BF}_{4}\right.$ )$_{1.2} \bullet 0.8 \mathrm{H}_{2} \mathrm{O}(2)$, $\left[\mathrm{Fe}(\mathrm{Htrz})_{2.05}(\operatorname{trz})_{0.75}\left(\mathrm{NH}_{2} \operatorname{trz}\right)_{0.2}\right]\left(\mathrm{BF}_{4}\right)_{1.25} \bullet 0.85 \mathrm{H}_{2} \mathrm{O}$ ( 3) and $\left[\mathrm{Fe}(\mathrm{Htrz})_{2}(\mathrm{trz})_{0.7}\left(\mathrm{NH}_{2} \mathrm{trz}\right)_{0.3}\right]\left(\mathrm{BF}_{4}\right)_{1.3} \bullet 0.95 \mathrm{H}_{2} \mathrm{O}(4)$. These tentative compositions indicate that the aminotriazole tends to replace the depronated triazolato ligand (trz) instead of the protonated $\mathrm{Htrz}$, in agreement with the increasing proportion of the $\mathrm{BF}_{4}^{-}$counter anion (see Table S1). Particle size and morphology of the different compounds were determined by transmission electron microscopy (TEM). Whatever the substitution rate, the images show aggregated nanoparticles of about $60 \mathrm{~nm}$ mean size with substantial size and shape distributions (see insert in figure 1 and Figure S2). Such inhomogeneity and aggregation of the nanoparticles is clearly associated with the synthesis method used to avoid the presence of additional surfactant/polymer.

Temperature dependent magnetic measurements carried out on samples 1-4 are presented in Figure 1. For each sample, we consider the transition temperature of the second thermal cycle, the first one corresponding to the dehydration of the sample. These data are gathered in Table 1 . The effect of ligand substitution on the spin crossover properties of $\left[\mathrm{Fe}(\mathrm{Htrz})_{2}(\operatorname{trz})\right]\left(\mathrm{BF}_{4}\right)$ nanoparticles is in agreement with that reported previously for the bulk material. Indeed, the transition temperature is shifted toward room temperature with increasing 4- $\mathrm{NH}_{2}$-triazole inclusion. At the same time, the hysteresis width and the abruptness of the transition decrease. These phenomena become more pronounced in sample 4.

Figure S3 shows representative Mössbauer spectra of sample 4 at 340 and $80 \mathrm{~K}$, while the corresponding hyperfine Mössbauer parameters at various temperatures are reported in table S2 for samples 1-4. For each sample, the residual HS fraction measured at $80 \mathrm{~K}$ is about $5-10 \%$ and thus does not seem to be influenced by the substitution of the triazole ligand (up to $10 \%$ alloying). For all samples, a constant relative proportion of the two spin states was evidenced in the investigated temperature range $(80-300 \mathrm{~K})$. The main goal of the Mössbauer study was to probe the influence of the ligand substitution on the lattice dynamics and the associated SCO hysteresis phenomena.

\begin{tabular}{|c|c|c|c|c|c|c|c|c|c|}
\hline Sample & $\begin{array}{l}T_{\text {up }} \\
\text { (K) }\end{array}$ & $\begin{array}{l}T_{\text {down }} \\
\text { (K) }\end{array}$ & $\begin{array}{l}\Delta \mathrm{T} \\
\text { (K) }\end{array}$ & $\begin{array}{l}T_{1 / 2} \\
\text { (K) }\end{array}$ & 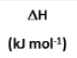 & $\begin{array}{c}\Delta \mathrm{S} \\
\left(\mathrm{J} \mathrm{K}^{-1} \mathrm{~mol}^{-1}\right)\end{array}$ & $\begin{array}{c}\Delta \mathrm{S}_{\mathrm{vib}} \\
\left(\mathrm{J} \mathrm{K}^{-1} \mathrm{~mol}^{-1}\right)\end{array}$ & $\begin{array}{l}\theta_{0}{ }^{\prime} \\
\text { (K) }\end{array}$ & $\begin{array}{l}\theta_{0}{ }^{d} \\
(\mathrm{~K})\end{array}$ \\
\hline 1 & 364 & 345 & 19 & 355 & 29 & 81 & 68 & 285 & 793 \\
\hline 2 & 354 & 340 & 14 & 347 & 19 & 57 & 44 & 226 & 801 \\
\hline 3 & 340 & 331 & 9 & 335 & 20 & 59 & 46 & 215 & 804 \\
\hline 4 & 330 & 325 & 5 & 327 & 18 & 56 & 43 & 205 & 791 \\
\hline
\end{tabular}

Table 1. Spin crossover parameters obtained from magnetic, calorimetric and Mössbauer measurements for samples 1-4. $T_{\text {down, }} \boldsymbol{T}_{\text {up }}$ $\Delta T, T_{1 / 2}, \Delta H, \Delta S, \Delta S_{v i b}, \theta_{D} f$ and $\theta_{D} \delta$ stand, respectively, for the spin transition temperature on heating and cooling, the hysteresis width, the barycentre of the hysteresis, the enthalpy, entropy and vibrational entropy changes associated with the SCO and the Debye temperatures determined from the temperature dependences of either the Mössbauer spectrum area or of the isomer shifts.

Indeed, ${ }^{57} \mathrm{Fe}$ Mössbauer spectroscopy can sensitively probe the lattice vibrational properties through the investigation of the temperature dependences of the Lamb-Mössbauer factor $(f)$ and the isomer shift $(\delta)$ [22]. The former is related to the meansquare amplitude of vibrations of iron atoms, while the latter to their mean-square velocity. In most cases, the temperature dependences of $f$ and $\delta$ are described using a simplified vibrational spectrum, such as the Debye model. In this frame, the lattice dynamics is characterized by a single parameter, the Debye temperature $\left(\theta_{D}\right)$, which can be regarded as a measure of the 'local' lattice stiffness around the iron atoms and reflects the elastic properties of the material. We must stress that the absolute values of $\theta_{D}$ extracted from the Mössbauer spectra are difficult to compare with those extracted from other methods (e.g. calorimetry or inelastic scattering). What is more, even the temperature dependences of $f$ and $\delta$ give usually rather different values $\left(\theta_{D} f\right.$ and $\theta_{D} \delta$, respectively). The reason for this is that these parameters provide a measure of a weighted average of the vibrational density of states (VDOS). In particular, for $\theta_{D} f$ resp. $\theta_{D} \delta$, the weight factors are proportional to $\omega^{-1}$ resp. $\omega$ and reflect therefore more the low resp. high frequency part of the vibrational spectrum [22].

Since the Lamb-Mössbauer factor is proportional to the full area $(A)$ of the Mössbauer spectrum (divided by the baseline), one can extract the Debye temperature $\left(\theta_{D} f\right)$ from a least squares fit of the temperature dependence of $A$ using the relationship $[22,23]$ :

$$
\log (A) \approx \log (C f)=\log (C)-\frac{3 E_{R}}{2 k_{B} \Theta_{D}}\left[1+4\left(\frac{T}{\Theta_{D f}}\right)^{2} \int_{0}^{\frac{\Theta_{D} f}{T}} \frac{\alpha}{\exp (\alpha)-1} \mathrm{~d} \alpha\right]
$$

with $C$ a constant, $E_{R}$ the recoil energy of iron, $k_{B}$ the Boltzmann constant, $T$ the temperature and $\alpha$ a variable for the integral (see Figure S4 for the fitted curves). For the non-substituted nanoparticle sample 1 , the obtained $\theta_{D} f$ value of $285 \pm 10 \mathrm{~K}$ in the LS state is one of the highest reported for a spin crossover compound and is in reasonable agreement with the value reported previously by Varek et al. [24] for the bulk compound (315 $\pm 12 \mathrm{~K})$. Indeed, typical low spin $\theta_{D}^{f}$ values of SCO compounds fall in the range of $140-250 \mathrm{~K}[17,24-29]$. Moreover, a decrease of $10-15 \%$ of the $\theta_{D}^{f}$ value was 
systematically determined when going from the LS to the HS state in agreement with the overall lattice expansion [17,30,31]. Interestingly, finite size effects on $\theta_{D} f$ were also reported for the 3D Hofmann clathrate coordination polymers [Fe(pyrazine) $\left.\left\{\mathrm{Ni}(\mathrm{CN})_{4}\right\}\right][28]$, for which the decrease of the particle size leads to a significant increase of $\theta_{D}$ from $170 \mathrm{~K}$ (110 $\mathrm{nm}$ particles) to $261 \mathrm{~K}$ ( $2 \mathrm{~nm}$ particles). This effect was associated with the modification of the elastic properties of the particles related to the strain induced by the surface.

Figure 2 represents the variation of $\theta_{D}^{f}$ as a function of the percentage of the triazole ligand substitution (see also Table 1). The striking observation here is the dramatic decrease of the Debye temperature from $285 \pm 10 \mathrm{~K}$ to $226 \pm 13 \mathrm{~K}$ for only 3.3 $\%$ aminotriazole ligand substitution. On the other hand, a less pronounced variation occurs for further ligand substitution, decreasing $\theta_{D} f$ to $205 \pm 15 \mathrm{~K}$ for ca. $10 \%$ substitution. It is interesting to note also that this latter value is substantially smaller than that reported previously for the pure bulk [Fe $\left.\left(\mathrm{NH}_{2} \mathrm{trz}\right)_{3}\right]\left(\mathrm{BF}_{4}\right)_{2}$ complex $(247 \pm 12 \mathrm{~K})$ [24]. Figure 2 shows also the variation of the Debye temperature extracted from the temperature dependence of the isomer shift $\left(\theta_{D}^{\delta}\right)$. The isomer shift data (Figure S5) were fitted using the equation [32]:

$$
\delta(\mathrm{T})=\delta_{o}+\frac{9 k_{B} \Theta}{16 M c} \delta-\frac{9 k_{B} T}{2 M c}\left(\frac{T}{{ }^{\Theta} \delta}\right)^{3} \int_{0}^{\Theta_{D} \delta / T} \frac{x 3}{\exp (x)-1^{\prime}} \mathrm{d} x
$$

where $c$ is the velocity of light, $M$ the mass of the ${ }^{57} \mathrm{Fe}$ atom, $\delta_{0}$ is the temperature independent part of the isomer shift and $x$ a variable for the integral. Remarkably, $\theta_{D} \delta$ remains constant within the experimental uncertainty upon the ligand substitution. From the markedly different behaviours of $\theta_{D} \delta$ and $\theta_{D}^{f}$ we can deduce that primarily the low frequency part of the VDOS is affected by the ligand substitution (i.e. the lattice phonons) whereas the vibrational modes of the coordination octahedron remain nearly unchanged. In other words, the origin of the stiffness decrease is associated to the modification of intermolecular forces. This conclusion is also in agreement with the observation that the spectral region of metal-ligand vibrations $\left(50-400 \mathrm{~cm}^{-1}\right)$ appears very similar in the Raman spectra of our samples (see Figure $\mathrm{S6}$ ).

Differential scanning calorimetry (DSC) measurements were also conducted on the different samples. In agreement with the magnetic data, the DSC peaks associated with the SCO shift to lower temperature when the quantity of the aminotriazole ligand increases (see Figure S7). Incidentally, the DSC curve for sample 4 revealed a tiny (ca. 2\%) additional peak at high temperature corresponding to the unsubstituted sample $\mathbf{1}$ denoting that $10 \%$ ligand substitution is the threshold from which phase segregation occurs. The primary aim of this DSC study was the assessment of the enthalpy $(\Delta H)$ and vibrational entropy $\left(\Delta S_{\text {vib }}=\Delta S_{\text {total }}-\Delta S_{\text {spin }}\right.$ with $\Delta S_{\text {spin }}=13 \mathrm{JK}^{-1} \mathrm{~mol}^{-1}$ for iron(II) SCO complexes) associated with the spin transition in the different samples (see Table 1). Remarkably, both $\Delta H$ and $\Delta S_{v i b}$ decrease by ca. $35 \%$ for only $3.3 \%$ aminotriazole ligand substitution, while further substitution does not bring any noticeable changes (within the experimental accuracy). This concomitant drop of the enthalpy and entropy provides a nice example for the so-called enthalpy-entropy compensation effect [33] and clearly parallels the collapse of the lattice stiffness, measured through $\theta_{D}{ }^{f}$.
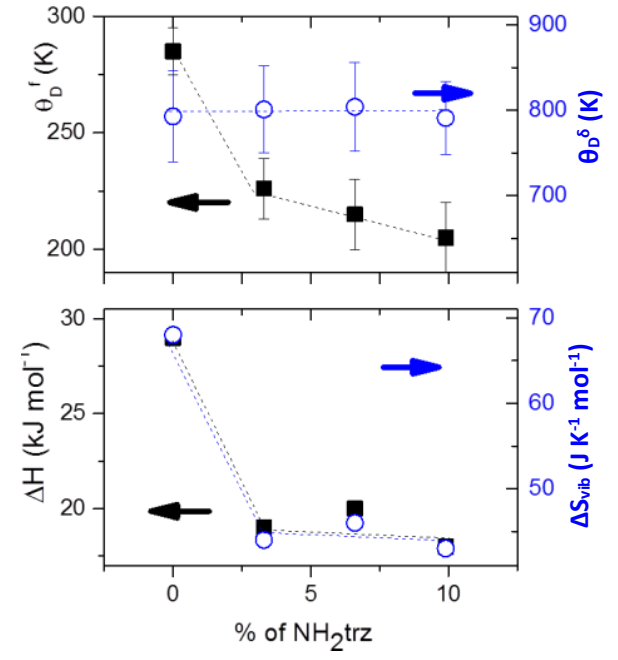

Figure 2. (Top panel) Debye temperatures obtained from the temperature dependence of the Mössbauer spectrum area (squares) and that of the isomer shift (circles) for samples 1-4 in the LS state. (Bottom panel) Excess enthalpy and vibrational entropy associated with the spin transition for samples 1-4.

We can propose the following physical picture to account for the different experimental observations. The introduction of the bulkier aminotriazole ligand strongly destabilizes the crystal lattice resulting in a reorganization of the interactions between the Fe-triazole chains, which are directly linked through $\mathrm{N}-\mathrm{H} \cdots \mathrm{N}$ interactions involving $\mathrm{Htrz}$ and trz ligands in the parent compound [34]. This leads to a decrease of the lattice cohesion energy - reflected unambiguously by the drop of $\theta_{D} f$. In line with this result, inspection of the room temperature (LS) powder X-ray diffraction patterns of 1 4 (see Figure 3), reveals a noticeable change between the structures of sample 1 and 2 .

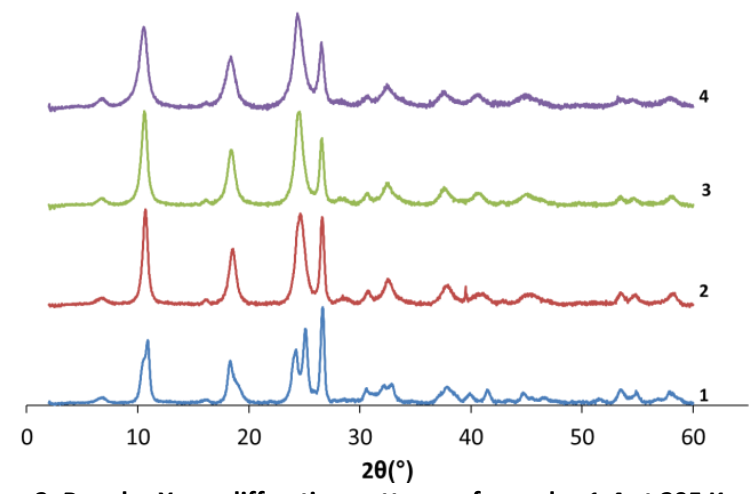

Figure 3. Powder X-ray diffraction patterns of samples 1-4 at $295 \mathrm{~K}$

Such observation is in perfect agreement with the structural data obtained for the same compound synthesized in different solvents [35]. On the other hand, further substitution does not seem to affect the structural organization, but results instead in a continuous broadening of the diffraction peaks and a slight downshift of the diffraction angles. These observations could be ascribed, respectively, to the disordering and expansion of the crystal lattice for increasing amount of aminotriazole ligands. In all probability, the 
collapse of the lattice cohesion must be more pronounced in the dense LS phase in comparison with the HS phase. As a first consequence, the cooperativity, which strongly depends both on the absolute value of the lattice stiffness as well as on the difference of the stiffness between the HS and LS phases, will also decrease, which is reflected in our experiments by a decrease of the hysteresis width Another consequence is that the values of both $\Delta H$ and $\Delta S_{\text {vib }}$ strongly decrease. Since the decrease of these two quantities has an opposite effect on the spin transition temperature, we can observe only a slight downshift of the transition curves.

\section{Conclusions}

In summary, surfactant free synthesis allowed us to elaborate a series of nanoparticle samples with the $\left[\mathrm{Fe}(\operatorname{trz})_{3 x}\left(\mathrm{NH}_{2} \mathrm{trz}\right)_{3}\right.$ $\left.{ }_{3 x}\right]\left(\mathrm{BF}_{4}\right)$ composition. Investigation of the ligand substitution effects revealed a pronounced change of the structural organisation associated with a dramatic drop of the lattice stiffness when introducing only a very small amount of aminotriazole ligand (3.3\%). Surprisingly, such significant structural modification has only a rather limited influence on the SCO behaviour, which we attribute to a delicate balance of different contributions to the enthalpy and entropy of the system, cancelling out their effects. To complete this study it would be important to assess the elastic properties of the samples in the HS phase and develop a more comprehensive thermodynamical model, which takes into account the concomitant effects of increasing disorder and lattice softening on the enthalpy and entropy of the two phases. Interestingly, the present work evidenced also a tightly linear enthalpy entropy compensation in our compounds. Such experimental observations have already been reported on different series of metal diluted SCO compounds [36] and the underlying physical mechanisms would deserve a deeper investigation.

\section{Conflicts of interest}

There are no conflicts to declare.

\section{Notes and references}

1. a) P. Gütlich, A Hauser and H. Spiering, Angew. Chem., Int., Ed. 1994, 33, 2024-2054. b) Spin Crossover in Transition Metal Compounds: Topics in Current Chemistry, Eds: P. Gütlich and H. A. Goodwin, Springer, Berlin, 2004. c) M. A. Halcrow Spin Crossover Materials: Properties and Applications, John Wiley \& Sons Ltd., New York, 2013.

2. G. Molnár, S. Rat, L. Salmon, W. Nicolazzi, A. Bousseksou, Adv. Mater. 2018, 30, 17003862.

3. K. Senthil Kumar, M. Ruben, Coord. Chem. Rev. 2017, 346 176-205.

4. A. Bousseksou, G. Molnar, L. Salmon et W. Nicolazzi , Chem. Soc. Rev. 2011, 40, 3313-3335.

5. H. J. Shepherd, G. Molnar, W. Nicolazzi, L. Salmon, A Bousseksou, Eur. J. Inorg. Chem., 2013, 653-661.

6. L. Salmon, L. Catala, Comptes Rendus Chimie, 2018, 21, 1230.

7. J. Kroeber, J.-P. Audiere, R. Claude, E. Codjovi, O. Kahn, J. G. Haasnoot, F. Groliere, C. Jay and A. Bousseksou, Chem. Mater. 1994, 6, 1404-1412.
8. J. R. Galán-Mascarós, E. Coronado, A. Forment-Aliaga, M Monrabal-Capilla, E. Pinilla-Cienfuegos and M. Ceolin, Inorg. Chem., 2010, 49, 5706-5714.

9. L.G. Lavrenova, V. N. Ikorskii, V. A. Varnek, I. M. Oglezneva and S. V. Larionov, Zh. Strukt. Khim. 1993, 34(6), 145

10. J. Krober, E. Codjovi, O. Kahn, F. Groliere and C. Jay, J. Am. Chem. Soc., 1993, 115, 9810-9811.

11. O. Kahn, C. J. Martinez, Science 1998, 279, 44-48.

12. O. G. Shakirova, L. G. Lavrenova, Yu. G. Shvedenkov, V. N. Ikorskii, V. A. Varnek, L. A. Sheludyakova, V. L. Varand, T. A. Krieger, and S. V. Larionov, J. Struct. Chem., Vol. 41, No. 5,

13. V. A. Varnek and L. G. Lavrenova, J. Struct. Chem., 1997, 38, 850-852.

14. E. Coronado, J. R. Galán-Mascarós, M. Monrabal-Capilla, J. Garciía-Martínez, P. Pardo-lbánez, Adv. Mater. 2007, 19, 13591361

15. S. Titos-Padilla, J. M. Herrera, X.-W. Chen, J.J. Delgado, E. Colacio, Angew. Chem. Int. Ed., 2011, 50, 3290-3293.

16. I. Suleimanov, J. Sanchez Costa, G. Molnár, L. Salmon, I. O Fritsky, A. Bousseksou, French Ukrainian J. Chem., 2015, 3, 1, 66. 17. M. M. Dîrtu, A. Rotaru, D. Gillard, J. Linares, E. Codjovi, B. Tinant and Y. Garcia, Inorg. Chem., 2009, 48, 7838-7852.

18. M. Mikolasek, M. D. Manrique-Juarez, H. J. Shepherd, K. Ridier, S. Rat, V. Shalabaeva, A.-C. Bas, I. E. Collings, F. Mathieu, J. Cacheux, T. Leichle, L. Nicu, W. Nicolazzi, L. Salmon, G. Molnár, A Bousseksou, J. Am. Chem. Soc. 2018, 140, 8970-8979.

19. L. Catala, T. Mallah, Coord. Chem. Rev., 2017, 346, 32v61

20. A. Tissot, L. Rechignat, A. Bousseksou M.-L. Boillot, J. Mater Chem., 2012, 22, 3411-3419.

21. M. Gimenez-Marques, M. Luisa Garcıa-Sanz de Larrea, E. Coronado, J. Mater. Chem. C, 2015, 3, 7946.

22. N. N. Greenwood, T. C. Gibb, Mössbauer spectroscopy Chapman and Hall Ltd. London 1971.

23. K. Boukheddaden, F. Varret, Hyperfine Interactions 1992, 72 349-356.

24. V. A. Varnek, L. G. Lavrenova, Journal of Structural Chemistry 1995, 36, 104.

25. S. Rat, M. Mikolasek, J. S. Costá, A. I. Chumakov, W. Nicolazzi G. Molnár, L. Salmon and A. Bousseksou, Chem. Phys. Lett., 2016 653, 131-136.

26. N. Moliner, L. Salmon, L. Capes, M. C. Muñoz, J.-F. Létard, A. Bousseksou, J.-P. Tuchagues, J. J. McGarvey, A. C. Dennis, M Castro, R. Burriel and J. A. Real, J. Phys. Chem. B, 2002, 106, 42764283

27. S. Rat, K. Ridier, L. Vendier, G. Molnár, L. Salmon, A.Bousseksou, CrystEngComm, 2017, 19, 3271.

28. H. Peng, S. Tricard, G. Felix, G. Molnur, W. Nicolazzi, L. Salmon, A. Bousseksou, Angew. Chem. Int. Ed. 2014, 53, $10894-10898$.

29. A. Nakamoto, H. Kamebuchi, M. Enomoto, N. Kojima, Hyperfine Interact, 2012, 205, 41.

30. A. A. Yousif, H. Winkler, H. Toftlund, A. X. Trautwein and R. H. Herber, J. Phys.: Condens. Matter, 1989, 1, 7103

31. J. P. Tuchagues, A. Bousseksou, G. Molnar, J. J. McGarvey, F Varret, Top. Curr. Chem. 2004, 235, 85-103.

32. J. Lindén, J.-P. Libäck, M. Karppinen, E.-L.Rautama, H. Yamauch, Solid State Communications, 2011, 151, 130-134

33. L. Liu, Q.-X. Guo, Chem. Rev. 2001, 101, 673-695

34. A. Grosjean, P. Négrier, P. Bordet, C. Etrillard, D. Mondieig, S Pechev, E. Lebraud, J.-F. Létard, P. Guionneau, Eur. J. Inorg. Chem., 2013, 796-802.

35. M. Michalowicz, J. Moscovici, B. Ducourant, D. Cracco, O Kahn, Chem. Mater. 1995, 7, 1833-1842.

36. (a) T. Tayagaki, A. Galet, G. Molnar, M. Carmen Munoz, A Zwick, K. Tanaka, J. -A. Real, A. Bousseksou, J. Phys. Chem. B 2005, 109, 14859-14867; (b) Martin J.P., Zarembowitch J. Dworkin A., Haasnoot J.G. and Codjovi E., Inorg. Chem. 33 (1994) 2617. 